\title{
Crystallization behavior and crystal properties of lactose as affected by lactic, citric, or phosphoric acid
}

\author{
R. Wijayasinghe, ${ }^{1}$ D. Bogahawaththa, ${ }^{1}$ J. Chandrapala, ${ }^{2}$ and T. Vasiljevic ${ }^{1 *}$ \\ ${ }^{1}$ Advanced Food Systems Research Unit, Institute of Sustainable Industries and Liveable Cities and College of Health and Biomedicine, \\ Victoria University, Werribee campus, Victoria 3030, Australia \\ ${ }^{2}$ School of Science, RMIT University, Bundoora, VIC 3083, Australia
}

\section{ABSTRACT}

The presence of acids in a lactose-containing system can affect its crystallization. The crystallization kinetics of lactose solutions were investigated as affected by lactic, citric, or phosphoric acid at a concentration of $0.05,1$, or $4 \%$ (wt/wt) as compared with that of pure lactose. The crystallization behavior of lactose was affected differently by the presence of all 3 acids and was mostly concentration dependent. The presence of 1 and $4 \%$ citric or phosphoric acid reduced the crystal yield significantly $(\geq 18 \%)$ as compared with that of pure lactose $(\sim 82 \%)$. Thermographic analysis of lactose crystals showed that the presence of $1 \%$ lactic, 0.05 and $1 \%$ citric, and $4 \%$ phosphoric acids in the lactose solutions induced the formation of amorphous lactose. X-Ray diffraction analysis revealed that the lactose crystallized mainly into $\alpha$-lactose monohydrate, stable anhydrous $\alpha$-lactose, and anhydrous crystals containing $\alpha$-lactose and $\beta$-lactose in a molar ratio of 5:3 and 4:1. Average size of the lactose particles, comprising of several crystallites, declined depending on the type of the acids and their concentration, but size of a single crystallite was not altered. The findings suggested that the lactose crystallization and crystal properties are governed by the lactose-water interactions, which can be influenced by the presence of acids in a concentration-dependent manner.

Key words: lactose, citric acid, phosphoric acid, lactic acid, crystallization, crystal properties

\section{INTRODUCTION}

Crystallization of lactose is an important process in the food industry, especially in the dairy sector, because its physical state can influence the storage stability and quality of various products. In many processes,

Received February 16, 2020.

Accepted August 7, 2020.

*Corresponding author: todor.vasiljevic@vu.edu.au the degree of sugar crystallinity is critical for the acceptance of the final product. For instance, crystallization of lactose is considered as a desired characteristic in products such as milk chocolate, but the presence of lactose crystals in milk powders, condensed milk, and ice cream hinders the quality of products (Lai and Schmidt, 1990; Martinez et al., 1990). The higher the degree of crystallization of lactose, the lower the proportion of amorphous lactose. Formation of amorphous lactose occurs when a lactose solution is dried quickly, leading to a rapid increase in viscosity of the solution, which results in insufficient time for the crystallization to take place (Roos, 2002). Thus, it is important to understand the principles that govern the formation or prevention of the crystalline sugar phase to develop satisfactory food products.

Lactose is often present in food systems in conjunction with other food constituents such as organic acids, salts, and proteins that can influence the process of lactose crystallization (Nijdam et al., 2007). These components can interfere with lactose crystallization by modifying both nucleation and crystal growth, for example, when manufacturing lactose from whey (Botsaris, 1982). According to Pisponen et al. (2014) and Raghavan et al. (2000), the crystallization of lactose in whey is a long process with an extended induction period for nucleation, which can result in uneven and large crystal size distribution. In some instances, the other food constituents may inhibit nuclei formation of lactose resulting in crystals with irregular-shaped and clumped arrangements (Gänzle et al., 2008). For example, the presence of proteins in a lactose solution can create localized lactose supersaturation spots, which induce nucleation and formation of a great number of small crystals (Mimouni et al., 2005). It has been reported that the presence of lactic acid (LA) in lactose solutions prevents lactose crystallization as it does not create a strong acidic environment $(\mathrm{pH}<2)$ to promote lactose crystallization (Jelen and Coulter, 1973; Nickerson and Moore, 1974; Huppertz and Gazi, 2016). Moreover, the growth of lactose crystals can be influ- 
enced by several processing-related and solution conditions including degree of supersaturation, solution $\mathrm{pH}$, temperature, and viscosity (Bhargava and Jelen, 1996; Rjabova et al., 2013). The degree of supersaturation is the primary factor, which directly influences crystallization, whereas other conditions affect the mutarotation and mass transfer rate (Wong and Hartel, 2014). It has also been reported that supersaturation can affect the growth rate and the shape of lactose crystals (Gänzle et al., 2008). The $\mathrm{pH}$ appears to affect the rate of mutarotation greatly. For example, the minimum mutarotation rate was observed at $\mathrm{pH} 5$, whereas $\mathrm{pH}$ below 2 and above 7 result in a rapid mutarotation rate (Huppertz and Gazi, 2016) confirming the importance of solution $\mathrm{pH}$ in lactose crystallization (Gänzle et al., 2008; Wong and Hartel, 2014).

Obviously, these crystallization conditions influence the crystal characteristics including the shape and size, which are important to achieve the ideal characteristics of the lactose-based products (Butler, 1998; Raghavan et al., 2000; Roos, 2009; Parimaladevi and Srinivasan, 2014). For instance, crystal forms or crystal morphology and crystal size are greatest areas of interest in food and pharmaceutical industries because the properties of lactose such as solubility, density, stability, and bioavailability directly depend on the polymorphs and the particle size (Barbosa-Cánovas et al., 2012). The scientific knowledge of kinetics of lactose crystallization, thermal behavior of lactose crystals, and their physical state in various food systems are of utmost importance when developing appropriate processing conditions, minimizing processing cost, and ensuring the quality of food products (Hartel, 2019). Hence, the current study was aimed at investigating thermal and physiochemical characteristics of lactose crystals and their behavior in model-based systems containing acids commonly used in the food industry as modifiers [LA, citric acid (CA), or phosphoric acid (PA)] at different concentrations. The scientific knowledge provided here may assist manufacturers to develop or optimize processing conditions through modifying the composition of selected acids in food systems comprising lactose.

\section{MATERIALS AND METHODS}

\section{Materials}

A local manufacturer (Murray Goulburn Co-operative Co. Ltd., Brunswick, VIC, Australia) kindly supplied the lactose powder. Lactic acid and PA (85\% wt/wt) were purchased from Sigma-Aldrich Pvt. Ltd. (Castle Hill, NSW, Australia). A CA solution ( $50 \%$ wt/wt) was prepared using a CA powder (Sigma-Aldrich Pvt. Ltd., Castle Hill, NSW, Australia).

\section{Preparation of Model Solutions}

Lactose powder (Murray Goulburn Co-operative Co. Ltd., Brunswick, Australia) was dissolved in Milli-Q water (Millipore Corporation, Bedford, MA) at $55^{\circ} \mathrm{C}$ $\pm 5^{\circ} \mathrm{C}$ to obtain a clear $40 \% \pm 0.5 \%$ (wt/wt) lactose solution. Then, the solution was filtered to remove any undissolved particles using a $0.45-\mu \mathrm{m}$ Whatman filter paper (Sigma-Aldrich Pvt. Ltd, Castle Hill, NSW, Australia). The resultant lactose solution was equally divided into 10 aliquots. To achieve the concentration ratios of lactose:acid at levels of 100:1 $(0.05 \% \mathrm{wt} / \mathrm{wt}$ acid to $5 \%$ wt/wt lactose), 5:1 (1\% wt/wt acid to $5 \%$ wt/wt lactose), or 5:4 (4\% wt/wt acid to $5 \% \mathrm{wt} /$ wt lactose), calculated amounts of LA, CA, or PA were added to the lactose (L) solutions (Wijayasinghe et al., 2019). These samples were coded as $\mathrm{L}+0.05 \mathrm{LA}, \mathrm{L}+1 \mathrm{LA}$, $\mathrm{L}+4 \mathrm{LA}, \mathrm{L}+0.05 \mathrm{CA}, \mathrm{L}+1 \mathrm{CA}, \mathrm{L}+4 \mathrm{CA}, \mathrm{L}+0.05 \mathrm{PA}$, $\mathrm{L}+1 \mathrm{PA}$, and $\mathrm{L}+4 \mathrm{PA}$. The pure lactose $(\mathbf{P L})$ without addition of any acids was considered the control. A rotatory evaporator (EYELA, Rikakikai Co. Ltd., Tokyo, Japan) was then used to concentrate all the samples to achieve $\sim 50 \%$ (wt/wt) TS (Wijayasinghe et al., 2015). Lactose concentration was determined using the Brix values measured by a refractometer (Atago Abbe, Tokyo, Japan) after calibration with water. The $\mathrm{pH}$ of all the concentrated lactose solutions was measured at $50 \pm 2^{\circ} \mathrm{C}$ using an inoLab pH7110 pH meter (WTW, Xylem Inc., Trifthof, Weilheim, Germany).

\section{Crystallization Procedure}

Crystallization of concentrated lactose solutions was performed using the method of Chandrapala et al. (2016). In brief, the concentrated solutions (at $55^{\circ} \mathrm{C}$ ) were rapidly cooled to the crystallization temperature of $30^{\circ} \mathrm{C}$ within $10 \mathrm{~min}$ and equilibrated at the same temperature for $2 \mathrm{~h}$ using a water bath consisting of a cooling unit to induce nucleation. Then, the solutions were slowly cooled down to $15^{\circ} \mathrm{C}$ at a rate of $5^{\circ} \mathrm{C} / \mathrm{h}$ and kept at the same temperature overnight with continuous stirring. The solutions were allowed to establish the mutarotation and attain the solubility equilibrium. The final solubility of the selected samples was determined by measuring concentration of the supernatants. The following day, the lactose crystals were filtered using $0.45-\mu \mathrm{m}$ filter papers and the separated lactose crystals were oven-dried at $80^{\circ} \mathrm{C}$ for $4 \mathrm{~h}$. The following equation was then used to calculate the percentage yield of lactose. When calculating the amount of lactose recovered, $5 \%$ water of crystallization of $\alpha$-lactose monohydrate was taken into account. The maximum solubility of lactose was considered as $17.84 \mathrm{~g}$ of lactose in $100 \mathrm{~g}$ of water at $15 \pm 1^{\circ} \mathrm{C}$ (Adhikari et al., 2018). Therefore, 
the maximum theoretical yield from $50 \%$ solution was considered to be $82.16 \mathrm{~g} / 100 \mathrm{~g}$ of water (Wong and Hartel, 2014):

$$
\text { yield }(\%)=\frac{0.95 \times \text { mass of lactose crystals obtained }}{\text { maximum theoretical crystal yield }} \times 100 \text {. }
$$

\section{Differential Scanning Calorimetry}

Differential scanning calorimetry (DSC) measurements of crystallized lactose samples were performed using a DSC instrument (DSC 1 STARe System, gas controller, GC 200, Mettler-Toledo, Columbus, OH) as previously explained (Wijayasinghe et al., 2015; Chandrapala et al., 2016) with slight modifications. Crystal samples were scanned at a heating rate of $10^{\circ} \mathrm{C} / \mathrm{min}$ starting from $50^{\circ} \mathrm{C}$ and ending at $250^{\circ} \mathrm{C}$. The STARe thermal analysis software (v. 15.00, Mettler-Toledo, Schwerzenbach, Switzerland) provided relevant information including the on-set, mid-point, and end-set temperatures and enthalpies of lactose crystal samples.

\section{Fourier-Transform Infrared Spectroscopy}

A Perkin Elmer Frontier FTIR spectrometer (Perkin Elmer, Waltham, MA) was used to collect the Fouriertransform infrared spectra (FTIR) in the 4,000 to $400 \mathrm{~cm}^{-1}$ range. Sample spectra were obtained in the absorbance mode after subtracting the background (Wijayasinghe et al., 2016). The spectral data in the region of 3,750 to $2,800 \mathrm{~cm}^{-1}$ were initially analyzed to study the interactions among system components. The generated peak areas related to constrained water molecules in the lactose crystals were quantified using the Origin software (Origin Pro 2018, v. 95E, OriginLab Corporation, Northampton, MA). Briefly, peak fitting procedure with the Gaussian function was used to identify and fit the peaks in the Fourier self-deconvoluted spectra and related peak areas were thus able to be quantified (Bogahawaththa et al., 2019).

\section{X-Ray Diffraction}

X-Ray powder diffraction patterns of all the samples were obtained using a Rigaku Miniflex 600 X-ray diffractometer (Rigaku Corporation, Wilmington, MA). The lactose powder samples were firmly pressed to form a thin film $(0.2 \mathrm{~mm})$ on the glass sample holders before loading them in the instrument. Operating conditions were set at $40 \mathrm{kV}$ and $15 \mathrm{~mA}$ and a step size of $0.02^{\circ}$ with a speed of $1.2 / \mathrm{min}$ from $2 \theta$ scanning range from $5^{\circ}$ to $30^{\circ}$ with $\mathrm{Ni} \mathrm{K} \beta$-filter (x2) and a D/ tex detector. The X-ray diffraction (XRD) data were analyzed by the Origin software (v. 95E) using a peak integration procedure with the Gaussian function. Degree of lactose crystallinity was calculated by dividing total area under the crystalline peaks by total area of the respective diffraction curve. The Scherrer formula was used to calculate average crystallite size (L):

$$
\mathrm{L}=\frac{\mathrm{K} \lambda}{\beta \times \cos \theta},
$$

where $\beta$ is the peak width of the diffraction peak profile at half maximum height resulting from small crystallite size in radians, $\theta$ is the Bragg angle, $\lambda$ is the $\mathrm{X}$-ray wavelength $(\mathrm{nm})$, and $\mathrm{K}$ is a constant associated with crystallite shape, generally considered as 0.9 (Scherrer, 1918).

\section{Particle Size Determination}

Average particle size was measured by a Mastersizer (Malvern-2000, Malvern Instruments Ltd., Malvern, UK) using the method previously reported (Chandrapala et al., 2016).

\section{Crystal Morphology Determined by Optical Light Microscopy}

The lactose crystal specimens were examined using a Motic advanced upright microscope (BA310, Motic China Group Co. Ltd., Hong Kong, China). The microscope was coupled with a camera and connected to a PC with a frame grabber to take and analyze images. Each sample was gently spread over a microscopic glass slide and images were captured to analyze crystal morphology. Several images $(\geq 8)$ were collected from each sample and crystal morphology was analyzed to obtain the most appropriate crystal representation from every sample.

\section{Statistical Analysis}

Results were analyzed by 1-way/2-way ANOVA using the SAS statistical software (v. 9.2). The level of significance was considered at $P<0.05$. The entire experiment was conducted in triplicate.

\section{RESULTS AND DISCUSSION}

\section{Crystal Yield of Lactose}

The PL solution yielded $\sim 82 \%$ of lactose crystals and its solubility was $17.6 \mathrm{~g} / 100 \mathrm{~g}$ of water (Table 1 ). It appeared that the crystal yield of lactose was not 
significantly $(P>0.05)$ reduced in the presence of LA at all 3 concentrations tested $(\mathrm{L}+0.0 .5 \mathrm{LA}, \mathrm{L}+1 \mathrm{LA}$, and $\mathrm{L}+4 \mathrm{LA})$ and $\mathrm{L}+0.05 \mathrm{CA}$ and $\mathrm{L}+0.05 \mathrm{PA}$ solutions in comparison to PL, whereas the solubility of the aforementioned samples were also not significantly different. However, when the concentration of $\mathrm{CA}$ or PA was increased from 0.05 to $1 \%$ and from 1 to $4 \%$, the crystal yield significantly decreased depending on the type of acids, which was directly related to the increased solubility of the same samples. For instance, in the presence of 1 and $4 \% \mathrm{CA}$, the yield was significantly reduced by $\sim 18$ and $26 \%$, respectively, in comparison to that of $\mathrm{L}+0.05 \mathrm{CA}$. The PA also hindered the crystal yield with an increase in its concentration from 0.05 to $1 \%$ mostly in a similar manner $(\sim 19 \%)$ to that of $\mathrm{CA}$, but $\mathrm{L}+4 \mathrm{PA}$ resulted in a greater $(P<0.05)$ reduction of lactose crystallization, by $\sim 35 \%$.

Obviously, the presence of acids in a lactose solution can severely affect the crystallization behavior of lactose (Botsaris, 1982) depending on the acid type and concentration (Table 1). This effect can mainly be ascribed to the chemical properties of the acids. Generally, the acids dissociate into hydrogen ions and their conjugate bases in a solution, but the propensity of releasing the hydrogen ions depends on their dissociation behavior. The weak acids with very low dissociation constants, such as lactic, citric, acetic, amino, fatty, and phosphoric acids, dissociate partly releasing only a few of their hydrogen ions into the solution. This leads to formation of hydronium ions with water via exceedingly strong hydrogen bonds (Belitz et al., 2009). According to the $\mathrm{p} K_{\mathrm{a}}$ values of LA $\left(\mathrm{p} K_{\mathrm{a}} 3.86\right)$, CA $\left(\mathrm{p} K_{\mathrm{a}} 1\right.$ 3.09, $\mathrm{p} K_{\mathrm{a}} 2$ 4.74, and $\left.\mathrm{p} K_{\mathrm{a}} 35.40\right)$, and PA ( $K_{\mathrm{a}} 12.15$, $\mathrm{p} K_{\mathrm{a}} 27.21$, and $\mathrm{p} K_{\mathrm{a}} 3$ 12.32), PA is the strongest and LA is the weakest acid. Thus, higher $\mathrm{H}^{+}$ion concentration (lower $\mathrm{pH}$ ) created by the PA can lead to formation of a strong hydration layer $\left(\mathrm{H}_{3} \mathrm{O}^{+}\right.$ion layer) around the lactose molecules interfering with integration of lactose molecules into the lactose crystals, resulting in the lowest crystal yield at its highest concentration. On the contrary, LA, being the weakest, resulted in a higher yield in comparison to the other acids, at respective concentration levels. On the other hand, the presence of these acids appeared to influence the solubility of lactose mainly by changing supersaturation of the solution and thereby lactose crystallization. The crystallization is a process composed of 2 basic steps: nucleation and the crystal growth (Wong and Hartel, 2014). The nucleation process in a solution begins with clustering and aggregation of molecules and ions. A nucleus should turn into a critical cluster size $(\sim 100-1,000$ atoms) to grow into a firm crystal (Sánchez-García et al., 2018). The supersaturation of the solution is the key factor for a nucleus to transform into a critical size.

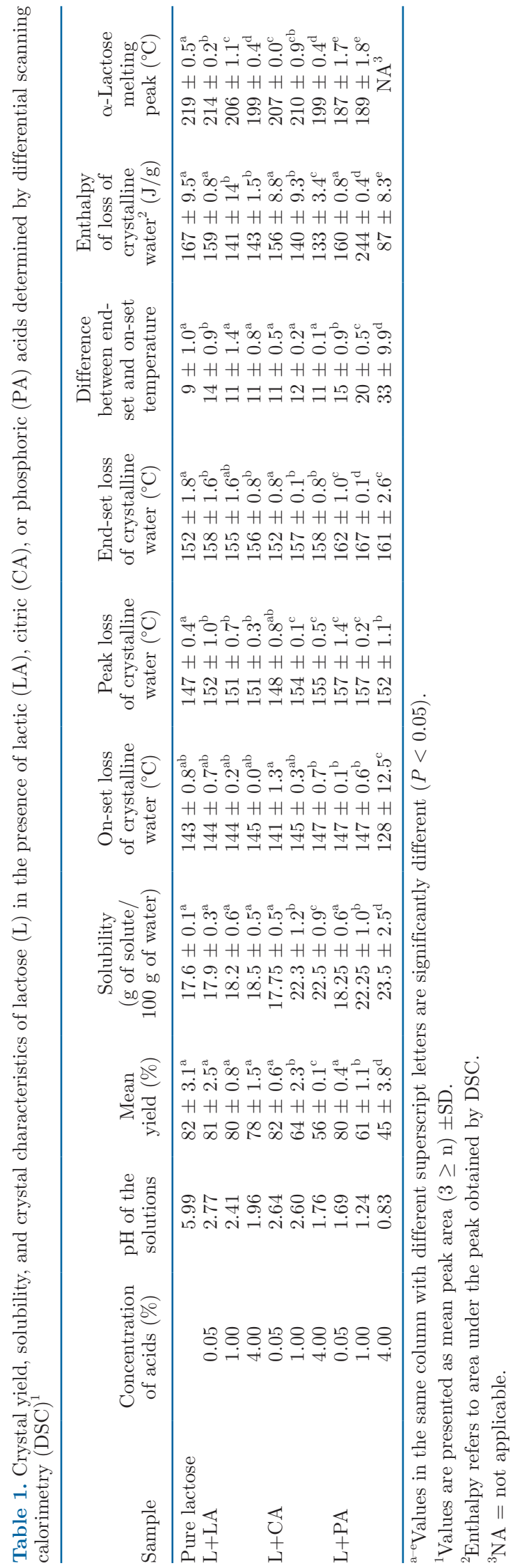


Nuclei, which are smaller than the critical size, tend to re-dissolve in the solution (Mandare and Pangarkar, 2003). In the current study, the presence of CA or PA at concentrations $\geq 1 \%$ increased the solubility of lactose in comparison to PL, which directly affected the supersaturation of the solution. This in turn altered the nucleation and crystal growth (Mullin, 1979) resulting in reduced yield of lactose crystals. Thus, current results indicate that nucleation and crystal growth were highly impeded by $4 \%$ PA in lactose solutions, in comparison to all other lactose solutions, which showed the highest solubility (23.5 g of lactose/76.5 g of water). On the other hand, $\mathrm{pH}$ plays an important role in solubility of a solution (Raghavan et al., 2001; Huppertz and Gazi, 2016; Sánchez-García et al., 2019). We observed an inverse relationship between the solubility and the $\mathrm{pH}$ in the present study (Table 1). According to Nickerson and Moore (1974) and Huppertz and Gazi (2016), the pH below 2 should enhance a rate of mutarotation and thereby increase the crystallization rate. However, in the present study, the low $\mathrm{pH}$ levels $(<2)$ did not enhance the lactose crystallization similar to observations by Visser (1980). Thus, in the present study, especially 1 and 4\% CA and PA acted as solvents or crystal growth inhibitors (Visser, 1980), resulting in reduced crystal yield.

Moreover, in our previous study (Wijayasinghe et al., 2019) we reported that, in the presence of CA or PA at $\leq 1 \%$ concentration, lactose can be partially hydrolyzed into glucose and galactose, which differ in solubility, leading to reduction of supersaturation of the entire system. Hence, the reduction of crystal yield in the equivalent solutions in the current study, especially $\mathrm{L}+1 \mathrm{CA}$ and $\mathrm{L}+1 \mathrm{PA}$, could be due to the presence of glucose and galactose molecules that can attach to the surface of the lactose crystals and obstruct the integration of lactose molecules and subsequent crystallization (Laos et al., 2007).

\section{Thermal Behavior of Lactose Crystals}

The thermal analysis of lactose crystals determined by DSC is presented in Table 1 . These DSC temperature peaks can be related to water of crystallization, behavior of surface water, and the presence or absence of amorphous and crystalline lactose and those of anomers (Listiohadi et al., 2009). Most of the crystal samples were characterized by the absence of an exothermic peak of crystallization, indicating that the obtained solids were in crystalline form (Figure 1). Furthermore, an appearance of an endothermic peak at $\sim 140$ to $150^{\circ} \mathrm{C}$ indicated the loss of crystalline water, which was incorporated into the crystal lattice during crystallization of $\alpha$-lactose. This endothermic peak further confirmed the crystallinity of those samples (Gombás et al., 2002). However, the crystallized lactose present in L+1LA, $\mathrm{L}+0.05 \mathrm{CA}, \mathrm{L}+1 \mathrm{CA}$, and $\mathrm{L}+4 \mathrm{PA}$ displayed a small exothermic peak after the first endothermic peak, which may be attributed to recrystallization of amorphous lactose present in the respective samples (Kaialy et al., 2011). The PL and all the other samples containing LA or CA demonstrated an endothermic peak at $\sim 200$ to $220^{\circ} \mathrm{C}$, which could be attributed to the melting of $\alpha$-lactose crystals (Gombás et al., 2002).

Moreover, all of the samples, with the exception of L+PA, appeared to have only one melting peak corresponding to the $\alpha$-lactose. This further highlighted the absence of $\beta$-lactose crystals. Interestingly, the melting peak of $\alpha$-lactose disappeared in the samples contain-
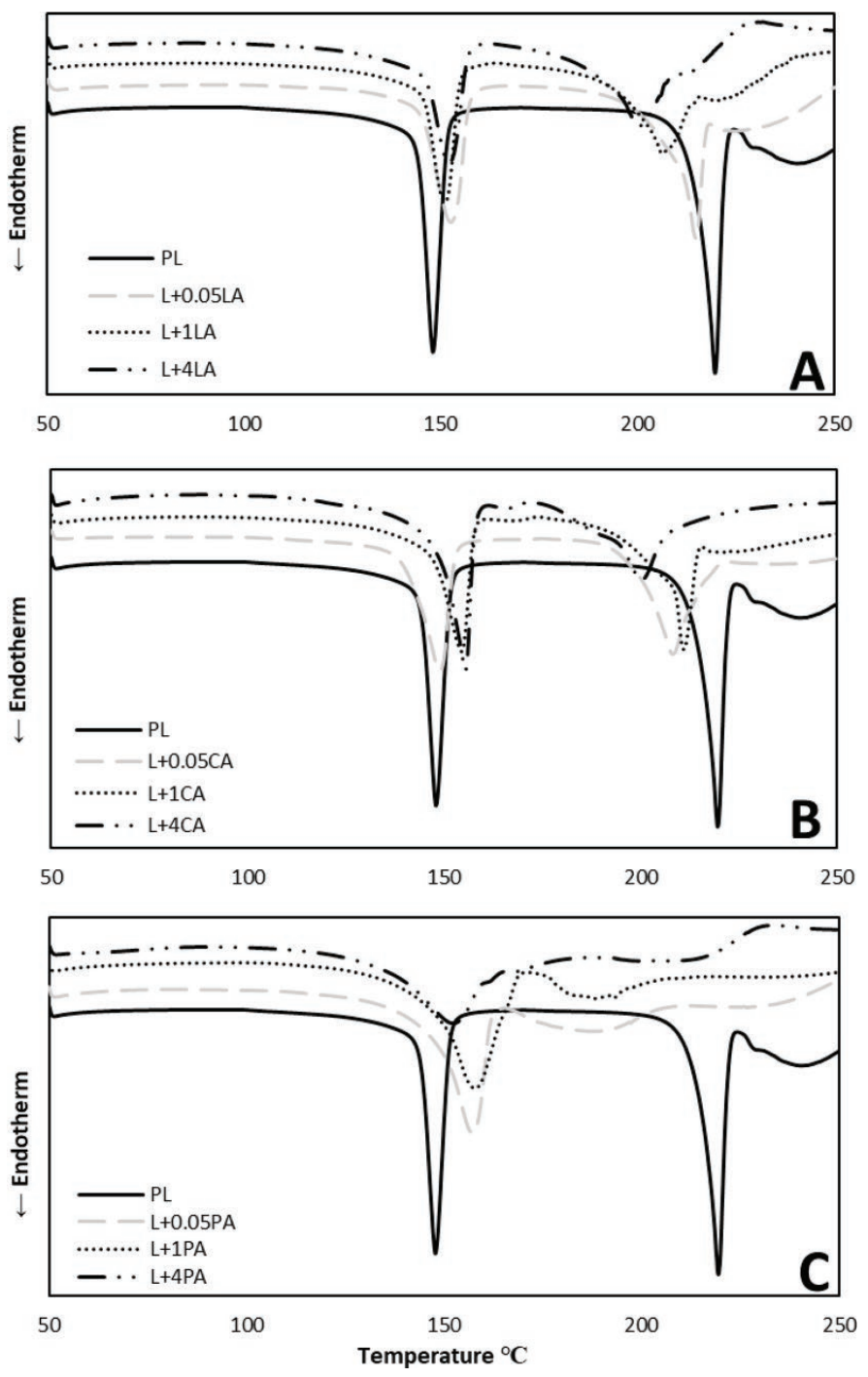

Figure 1. Dynamic differential scanning calorimetry curves for lactose $(\mathrm{L})$ crystals in the presence of lactic (LA; A), citric $(\mathrm{CA} ; \mathrm{B})$, or phosphoric (PA; C) acids at a concentration of $0.05,1$, or $4 \%(\mathrm{wt} / \mathrm{wt})$ and pure lactose (PL). 
ing PA, possibly due to highly deformed structure, or this peak may have moved to a higher temperature $\left(>250^{\circ} \mathrm{C}\right)$ beyond the temperature range applied in the present study. Generally, either type or concentrations of the acids tested did not affect the on-set, end-set, and peak temperatures $(P>0.05)$, but the on-set of crystalline water evaporation was significantly reduced in L+4PA as compared with PL. In contrast, the enthalpies of crystalline water evaporation were reduced in all samples as compared with PL except L+1PA, which requires further elaboration. These reduced enthalpies of crystalline water evaporation could be attributed to obstruction of water removal from the crystal lattice (Wijayasinghe et al., 2015; Chandrapala et al., 2016). Commonly, the temperature range between on-set and end-set temperatures, which is associated with the loss of crystalline water from lactose crystals, widened substantially $\left(11-33^{\circ} \mathrm{C}\right)$ in all the samples in comparison to PL $\left(\sim 9^{\circ} \mathrm{C}\right)$. The highest range of dehydration temperature $\left(\sim 15-33^{\circ} \mathrm{C}\right)$ was reported for the samples containing PA, where higher concentration contributed to the greater association of water with the crystals hindering its evaporation. Widening of the peaks of water evaporation also indicated the deceleration of the crystallization process, which can be attributed to the formation of stronger hydration layer around the lactose molecules.

Additionally, we observed another endothermic peak region at $\sim 160$ to $170^{\circ} \mathrm{C}$ in $\mathrm{L}+4 \mathrm{CA}$ sample, which might be ascribed to the transformation of $\alpha$-lactose monohydrate into its stable lactose anhydrous form (Kirk et al., 2007) and eventually contribute to formation of more crystalline lactose. This transformation could be induced by high thermal energy generated at high temperatures, but possibly reversible under high humidity $(>50 \%)$ conditions. However, this peak was also previously suggested to indicate the melting of unstable anhydrous $\alpha$-lactose (Islam and Langrish, 2010) or as a water dehydration peak (Berlin et al., 1971).

\section{Crystal Morphology of Lactose}

The morphology of lactose crystals obtained from the microscopic analysis is depicted in Figure 2. All the samples showed slight deviation in comparison to the characteristic tomahawk morphology of $\alpha$-lactose crystals (Figure 2A) in the presence of tested acids. Lactose crystals transform into a variety of shapes depending on the solution environment that may affect the growth rate of crystal faces (van Kreveld and Michaels, 1965). Crystals grown in PL solution developed with a tomahawk morphology. In L+0.05LA and L $+1 \mathrm{CA}$ solutions, crystals were nucleated with fully developed tomahawk morphology with a very small (0ī0) face and a large
( $0 \overline{1} \overline{1})$ face (Dincer et al., 2009). In L+0.05CA solution, crystals were nucleated with a tomahawk blade sharpened morphology (Figure 2c; Holsinger, 1988), where the $(0 \overline{1} 0)$ face became sharpened due to slower transport of solvent molecules into the crystal lattice. These crystals have a noticeable ( $0 \overline{1} 1)$ face, because it is the slowest developing face. These results indicate that the solution $\mathrm{pH}$ above 2 or below 2 can result in crystals with the tomahawk and triangular morphologies with or without irregular faces, respectively (Figure $2 \mathrm{~d}$, e, $f, h, i, j)$. Notably, in the presence of PA at all of the concentrations tested, the lactose crystals were developed with the triangular morphology (Figure $2 \mathrm{~d}, \mathrm{f}, \mathrm{j}$ ). This can be related to reduction of the supersaturation of lactose solution due to the hydrolysis as explained by Herrington (1934). Further studies are however required to elucidate how the presence of different acids in the lactose solutions modulate crystallization velocity of the lactose and the crystalline forms. However, it is well established that the presence of impurities in crystallizing solution can result in the morphological changes due to their possible absorption into the faces of growing crystals. The lactose crystals with irregular faces were thus formed in the presence of acids due to incorporation of likely acid molecules into the crystal lattice and consequent interruption of the rhythmic packing arrangement of lactose molecules to form a crystal (Berkovitch-Yellin et al., 1985).

\section{Water Behavior of Lactose Crystals Determined by FTIR}

The FTIR analysis was used to elucidate the water behavior of lactose crystals in different samples as shown in Figure 3. The spectral region of 3,600 to 3,200 $\mathrm{cm}^{-1}$ depicts the behavior of water molecules (Wolkers et al., 1998). All the samples showed broad vibration bands in this region that correspond to intermolecular stretching vibrations of hydroxyl groups (Kirk et al., 2007; Kaialy et al., 2011). However, variations of these stretching vibrations can be observed depending on the acid type and their concentration in different samples. This highlighted that the vibrations have been either restricted or expanded due to the nature of interactions between acids, water, and lactose. For example, restricted stretching vibrations can be observed in L+4CA and L+1LA indicating the presence of more intermolecular interactions and less water in comparison to PL (Chandrapala et al., 2016), whereas expanded stretching vibrations were observed in all other samples. In the $\mathrm{L}+4 \mathrm{CA}$ sample, the intensity of intermolecular stretching vibrations of hydroxyl groups largely reduced due to increased concentration of CA molecules that resulted in enhanced interactions between acid molecules rather 
A
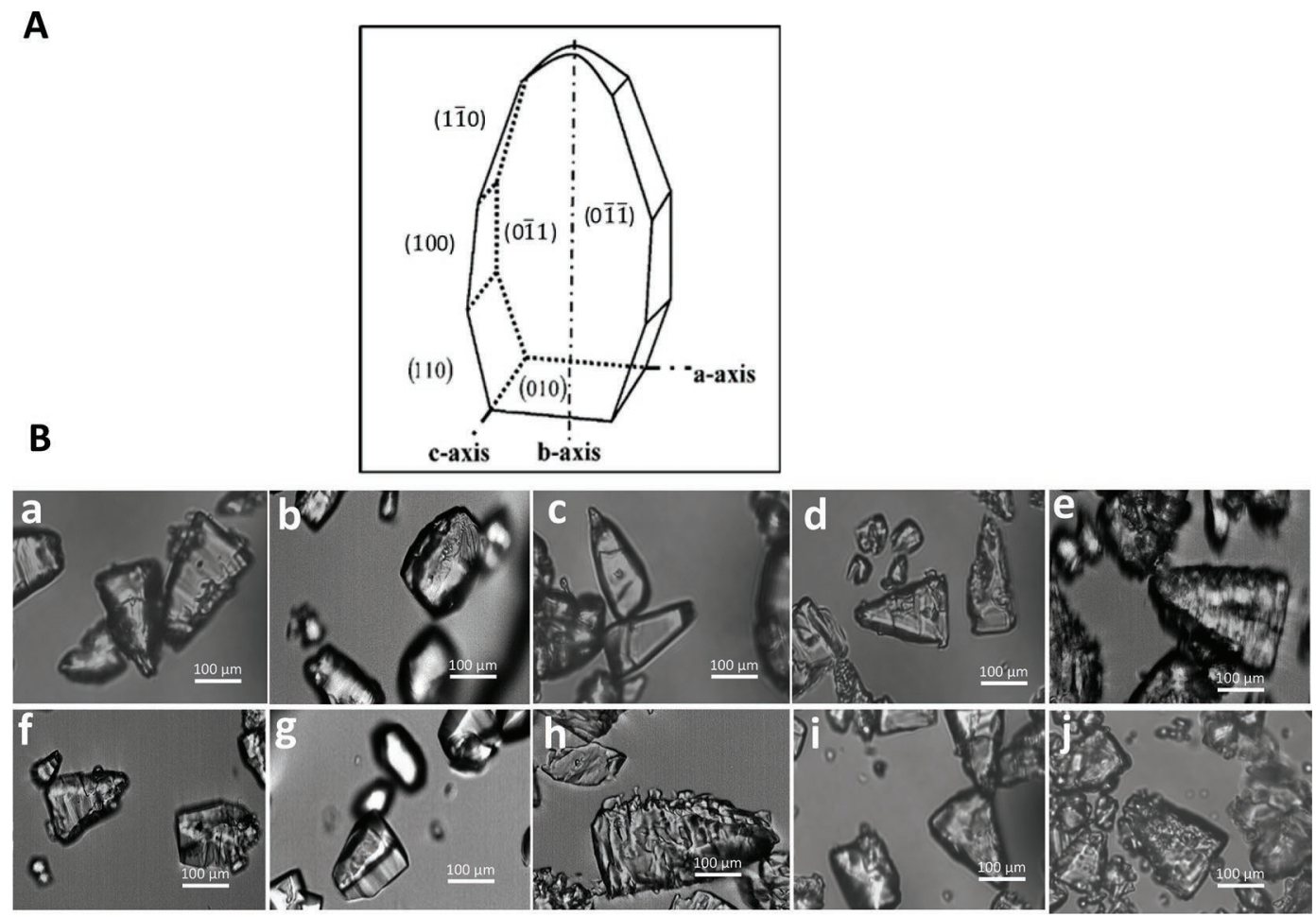

Figure 2. Characteristic tomahawk morphology of $\alpha$-lactose monohydrate crystal (A) and crystal morphology of lactose in the presence of the acids (B) pure lactose (a), lactose $+0.05 \%$ lactic acid (b), lactose $+0.05 \%$ citric acid (c), lactose $+0.05 \%$ phosphoric acid (d), lactose + $1 \%$ lactic acid (e), lactose $+1 \%$ citric acid (f), lactose $+1 \%$ phosphoric acid (g), lactose $+4 \%$ lactic acid (h), lactose $+4 \%$ citric acid (i), and lactose $+4 \%$ phosphoric acid $(\mathrm{j})$.

than interacting with the water molecule. Similarly, in the presence of $1 \mathrm{LA}$, stretching vibrations of hydroxyl groups were highly reduced, which can be attributed to differences in hydrogen bonding, affected by LA concentration within the crystal lattice (Chandrapala et al., 2016) that limited the mobility of free water molecules. The stretching vibrations were highly expanded in $\mathrm{L}+4 \mathrm{LA}, \mathrm{L}+0.05 \mathrm{CA}$, and $\mathrm{L}+4 \mathrm{PA}$ displaying greatly restricted mobility of water molecules. These observations apparently indicate changes in molecular mobility of water molecules and structural changes of lactose crystals depending on the acid type and concentration as explained previously by Reid and Fennema (2008). Additionally, the monohydrate form of lactose exhibited a sharp and distinct peak at 3,524 to $3,522 \mathrm{~cm}^{-1}$ indicating the stretching of $\mathrm{O}-\mathrm{H}$ bonding (Kirk et al., 2007). The location and shape of this peak indicate the constrained water molecules contained in the crystal lattice. This peak was more pronounced in $\mathrm{L}+0.05 \mathrm{LA}$, $\mathrm{L}+4 \mathrm{LA}, \mathrm{L}+0.05 \mathrm{CA}$, and $\mathrm{L}+4 \mathrm{PA}$ than that of PL, highlighting the presence of more restricted water molecules in the crystal lattice. This was further confirmed by the results of peak area quantification (Table 2) showing a significant $(P<0.05)$ increase in the peak areas in the above samples as compared with PL. Greater peak area indicates the presence of strong interactions between water and acids, indicating the presence of more water molecules in the crystal lattice (Raut et al., 2001) especially in L+4PA sample. This sample also showed a greater association of water with crystals, displayed by DSC results through a wider range of dehydration temperature $\left(\sim 33^{\circ} \mathrm{C}\right)$, and a lower water evaporation enthalpy in comparison to other samples, which altogether hindered the evaporation of water from the crystal lattice.

\section{Characterization of Lactose Crystals by XRD}

Characteristic XRD patterns of the lactose crystals were depicted in Figure 4. The location of the peaks (2 $\theta)$ represents the different types of lactose crystals present in the sample, for instance $\alpha$-lactose at $12.5^{\circ}, 16.4^{\circ}$, $20.0^{\circ}$, and $20.1^{\circ}$ and anhydrous $\beta$-lactose at $10.5^{\circ}, 20.9^{\circ}$, and $21.0^{\circ}$. A few other peaks have been assigned to the mixtures of lactose crystals, for instance anhydrous $\alpha: \beta$ with a molar ratio of $5: 3$ at $19.1^{\circ}$ and $21.1^{\circ}$ and anhydrous $\alpha: \beta$ with a molar ratio of $4: 1$ at $19.5^{\circ}$ (DrapierBeche et al., 1998). In the present study, crystallization of lactose into the form of $\alpha$-lactose monohydrate can be observed by the peaks at $12.8^{\circ}-13.3^{\circ}, 16.7^{\circ}-16.9^{\circ}$, 

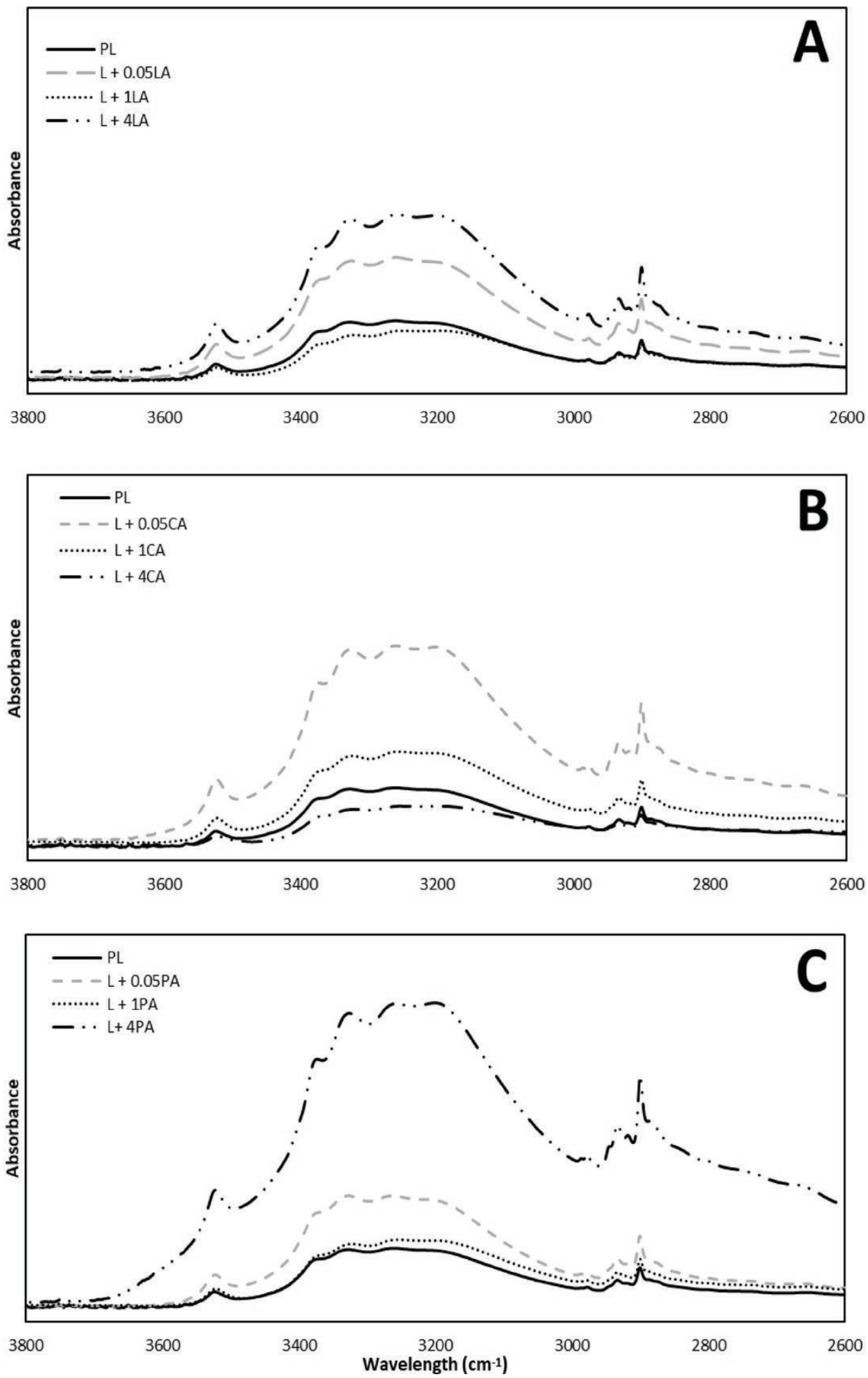

Figure 3. Fourier-transform infrared spectra obtained from the lactose (L) crystals comprising lactic (LA; A), citric (CA; B), or phosphoric $(\mathrm{PA} ; \mathrm{C})$ acids at a concentration of $0.05,1$, or $4 \%(\mathrm{wt} / \mathrm{wt})$ and pure lactose $(\mathrm{PL})$. 
$19.9^{\circ}, 20.0^{\circ}$, and $20.1^{\circ}$ (Table 3 ) in almost all of the samples tested. However, crystallization of lactose into the anhydrous $\beta$-lactose could not be detected in any sample at respective diffraction angles. The slight deviations of the diffraction angles in the present study, in comparison to the previous data (Haque and Roos, 2005), could be related to increased space between crystal layers created by interactions of acids with water and lactose. The peak assigned to the stable anhydrous $\alpha$-lactose $\left(19.3^{\circ}\right)$ was observed only in L+4CA (Table 3 ), which coincided with the DSC endothermic peak appeared at $\sim 160$ to $170^{\circ} \mathrm{C}$ in the same sample.

Moreover, we observed a peak related to the mixture of anhydrous $\alpha: \beta$ with a molar ratio of $4: 1$ at $\sim 19.5^{\circ}$ in all the samples tested including PL, indicating that all the acids tested had no considerable effect on formation of this crystal mixture. However, the crystals with $\alpha$-lactose and $\beta$-lactose in molar ratio of $5: 3$ were formed only in L+1CA and L+1PA as displayed by a peak at $21.1^{\circ}$. The formation of different types of lactose crystals varies in different food systems mainly due to interactions between lactose and other components present in the system leading to changes in supersaturation, diffusion of lactose molecules, and mutarotation of molecules during nucleation and crystal growth stages (Nijdam et al., 2007). Therefore, variations in the crystal types observed between the present and other studies could be ascribed to the differences in intra- and intermolecular interactions between acids and lactose as already discussed above and differences in crystallization conditions.

The crystalline lactose exhibited several sharp distinct diffraction peaks in the range of 19 to $20^{\circ}(2 \theta)$ as the main signals in all the samples tested (Figure 4). However, the differences in peak intensities could

Table 2. Peak areas of the lactose crystals related to constrained water molecules as determined by the Fourier-transform infrared spectra peak area analysis ${ }^{1}$

\begin{tabular}{lccr}
\hline Sample & $\begin{array}{c}\text { Acid } \\
\text { concentration } \\
\text { \% wt/wt) }\end{array}$ & $\begin{array}{c}\text { Wave } \\
\text { number } \\
\left(\mathrm{cm}^{-1}\right)\end{array}$ & $\begin{array}{c}\text { Mean } \\
\text { peak } \\
\text { area }\end{array}$ \\
\hline Pure lactose & 0 & 3,523 & $4.9 \pm 0.4^{\mathrm{a}}$ \\
L+LA & 0.05 & 3,523 & $9.9 \pm 0.8^{\mathrm{b}}$ \\
& 1.00 & 3,522 & $4.7 \pm 0.4^{\mathrm{a}}$ \\
L+CA & 4.00 & 3,523 & $13.3 \pm 1.3^{\mathrm{c}}$ \\
& 0.05 & 3,524 & $15.2 \pm 1.2^{\mathrm{c}}$ \\
L+PA & 1.00 & 3,523 & $8.2 \pm 0.8^{\mathrm{b}}$ \\
& 4.00 & 3,523 & $3.8 \pm 0.2^{\mathrm{a}}$ \\
& 0.05 & 3,524 & $9.0 \pm 0.8^{\mathrm{b}}$ \\
& 1.00 & 3,522 & $6.1 \pm 0.4^{\mathrm{a}}$ \\
& 4.00 & 3,523 & $17.7 \pm 1.6^{\mathrm{d}}$ \\
\hline
\end{tabular}

${ }^{\mathrm{a}-\mathrm{d}}$ Values in the same column with different superscript letters are significantly different $(P<0.05)$.

${ }^{1}$ Values are presented as mean peak area $(3 \geq \mathrm{n}) \pm \mathrm{SD} . \mathrm{L}=$ lactose; $\mathrm{LA}=$ lactic acid; $\mathrm{CA}=$ citric acid; and $\mathrm{PA}=$ phosphoric acid.
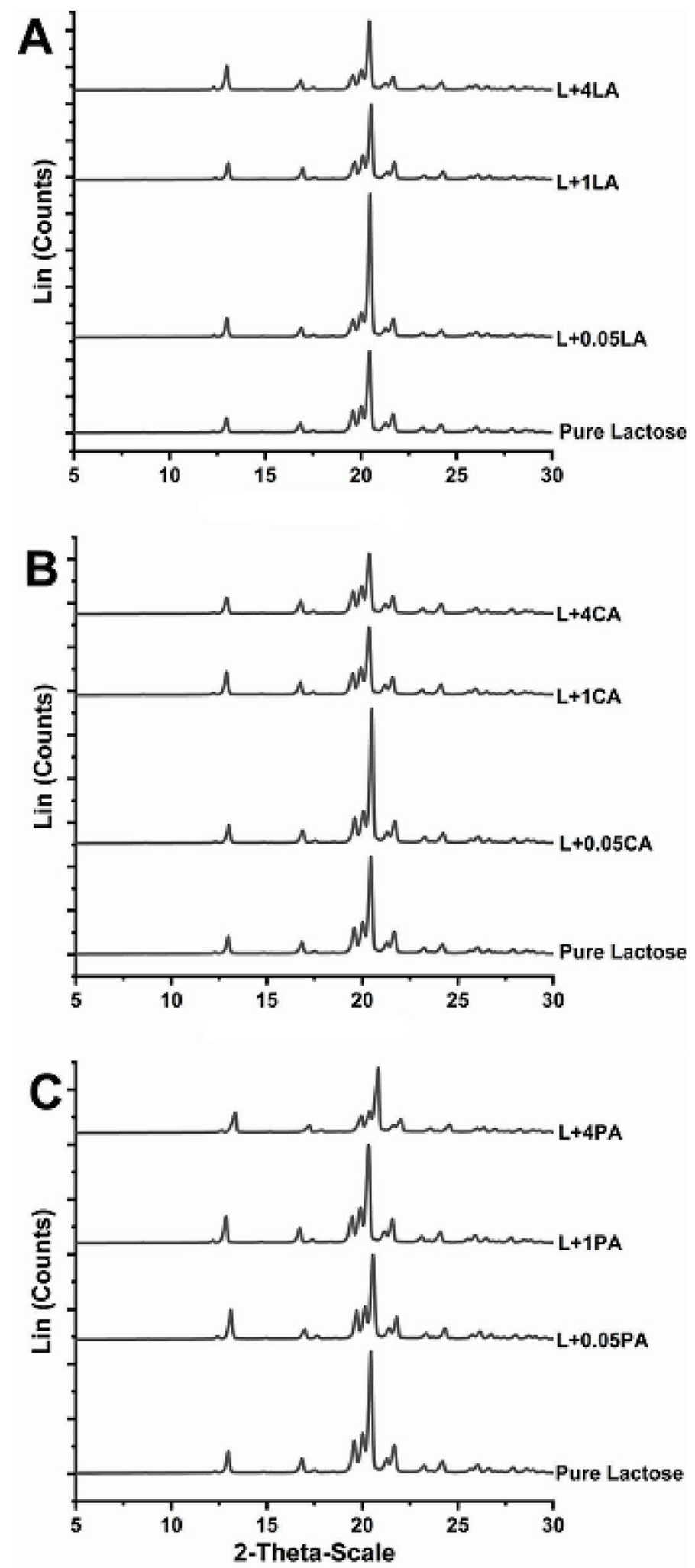

Figure 4. X-Ray diffraction patterns of lactose (L) crystals with addition of lactic (LA; A), citric (CA; B), or phosphoric (PA; C) acids at a concentration of $0.05,1$, or $4 \%$ (wt/wt) and pure lactose (PL). Lin $=$ number of reflections raised due to the crystal planes. 


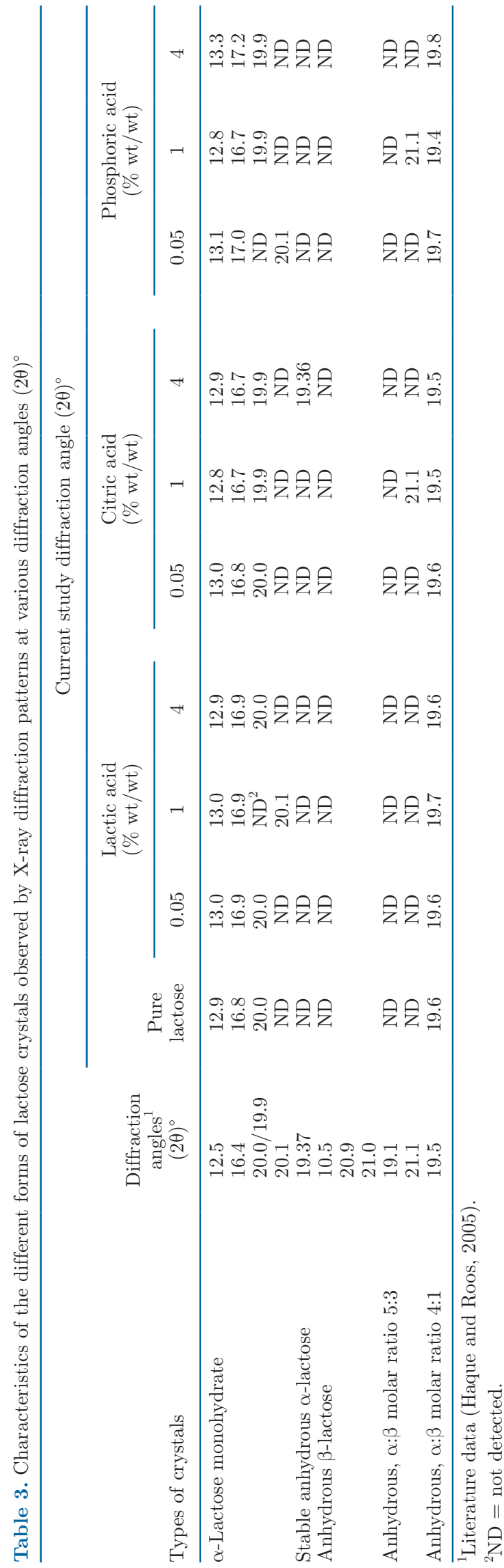

be related to changes in degree of lactose crystallinity depending on types and concentration of the acids tested as shown in Table 4. The highest degree of lactose crystallinity was recorded in $\mathrm{L}+4 \mathrm{CA}$ while lowest in $\mathrm{L}+0.05 \mathrm{LA}$ in comparison to PL. To form crystalline materials, lactose molecules should be arranged or connected in a regularly repeating pattern or a lattice through van der Waals attractions and hydrogen bonds (Walstra, 2003). However, the interactions between acid molecules and lactose may form lactose-water-acid complexes and obstruct the well-ordered arrangement and bonding pattern of lactose molecules interfering the process of lactose crystallization (Wijayasinghe et al., 2015). For example, in the present study, the LA appeared to highly interact with water and lactose to reduce the orderly arrangement of lactose molecules in $\mathrm{L}+0.05 \mathrm{LA}$ and thereby reduce lactose crystallinity. This could be attributed to the behavior of electron cloud around the LA molecule. Lactic acid is the smallest molecule based on its electron cloud in comparison to other examined acids. Thus, $0.05 \%$ of LA strongly interacts with lactose and water, as explained above, leading to formation of lactose-lactic acid-water complexes. The CA possibly increased the water-acid or acid-acid interactions (or both), allowing lactose molecules to interact together under minimal free energy to form crystal lattice (Wijayasinghe et al., 2019).

The average particle size of crystallite lactose (determined by a Mastersizer) was substantially reduced in the presence of all the acids tested in comparison to PL and the trend was mostly concentration dependent (Table 4). The differences in the particle size can be attributed to the hydrophilic nature of the acid molecules and their ability to bind water. However, as discussed earlier, water molecules that are hydrogen bonded with 4 different $\alpha$-lactose molecules can obstruct removal of water, causing defects in lactose crystals and eventually forming different particle sizes (Nickerson, 1954). Furthermore, reduction of supersaturation of lactose, affected by increase in the acid concentration, may prevent aggregation of crystals, resulting in smaller particle sizes. Additionally, the van der Waals interactions between crystals can be interfered with by acid molecules due to formation of water-acid-lactose complexes. This can contribute to hindering the aggregation of nucleated crystals and loss of their uniformity, resulting in smaller particles. The average crystallite size of lactose (determined by XRD) was not substantially changed across all the samples (Table 4). It appeared that the crystallite size was always smaller than corresponding particle size since the XRD usually captures crystallite contained in the particles (Monshi et al., 2012). However, the crystallite size was not affected by the presence of the tested acids. 
Table 4. Crystallinity, particle size, and crystallite size of the lactose

\begin{tabular}{|c|c|c|c|c|}
\hline Sample $^{1}$ & $\begin{array}{c}\text { Acid concentration } \\
(\% \mathrm{wt} / \mathrm{wt})\end{array}$ & $\begin{array}{c}\text { Average degree } \\
\text { of crystallinity }{ }^{2}(\%)\end{array}$ & $\begin{array}{l}\text { Average particle } \\
\operatorname{size}^{3}(\mathrm{~nm})\end{array}$ & $\begin{array}{l}\text { Average crystallite } \\
\operatorname{size}^{2}(\mathrm{~nm})\end{array}$ \\
\hline Pure lactose & 0 & $79.5^{\mathrm{ab}}$ & $142 \pm 4 \times 10^{3}$ & $319 \pm 61$ \\
\hline \multirow[t]{2}{*}{$\mathrm{L}+\mathrm{LA}$} & 0.05 & $73.3^{\mathrm{c}}$ & $121 \pm 4 \times 10^{3}$ & $347 \pm 80$ \\
\hline & 4.00 & $79.9^{\mathrm{b}}$ & $69 \pm 2 \times 10^{3}$ & $311 \pm 69$ \\
\hline \multirow{2}{*}{$\mathrm{L}+\mathrm{CA}$} & 0.05 & $77.3^{\mathrm{d}}$ & $118 \pm 18 \times 10^{3}$ & $331 \pm 65$ \\
\hline & 1.00 & $82.3^{\mathrm{f}}$ & $112 \pm 31 \times 10^{3}$ & $315 \pm 54$ \\
\hline \multirow{2}{*}{$\mathrm{L}+\mathrm{PA}$} & 1.00 & $81.7^{\mathrm{e}}$ & $71 \pm 9 \times 10^{3}$ & $317 \pm 54$ \\
\hline & 4.00 & $77.9^{\mathrm{g}}$ & $87 \pm 16 \times 10^{3}$ & $259 \pm 43$ \\
\hline
\end{tabular}

${ }^{\mathrm{a}-\mathrm{h}}$ Values in the same column with different superscript letters are significantly different $(P<0.05)$.

${ }^{1} \mathrm{~L}=$ lactose; $\mathrm{LA}=$ lactic acid; $\mathrm{CA}=$ citric acid; and $\mathrm{PA}=$ phosphoric acid.

${ }^{2}$ Determined by X-ray diffraction.

${ }^{3}$ Determined by Mastersizer (Malvern-2000, Malvern Instruments Ltd., Malvern, UK).

\section{CONCLUSIONS}

The crystallization behavior of lactose is mostly affected by the type and concentration of the acids present in the lactose systems. Evidently, interactions of lactose with water and acids modulate the crystalline habits of lactose. The presence of $1 \% \mathrm{LA}, 0.05$ and $1 \%$ $\mathrm{CA}$, and $4 \% \mathrm{PA}$ can result in formation of amorphous lactose during crystallization, whereas stable anhydrous $\alpha$-lactose is produced in the presence of $4 \% \mathrm{CA}$. The presence of either $\mathrm{CA}$ or $\mathrm{PA}$ at $\geq 1 \%$ can cause a greater reduction of crystal yield $(\geq 18 \%)$. Moreover, the particle size and crystal shapes are affected depending on the type and concentration of the acid present in the lactose solutions. Therefore, appropriate selection of processing conditions, acid types, and their concentration are important for the crystallization of lactose present in a complex mixture because lactose nucleation and crystallization can be governed by behavior and properties of the solvent water that is considerably influenced by the presence of acids. Therefore, the present study emphasizes the importance of controlling lactose-water interactions and anomeric equilibrium of lactose to achieve a proper crystallization process.

\section{ACKNOWLEDGMENTS}

The authors are grateful to the Victoria University for providing financial and technical support. The authors have not stated any conflicts of interest.

\section{REFERENCES}

Adhikari, B. M., T. Truong, N. Bansal, and B. Bhandari. 2018. Influence of gas addition on crystallisation behaviour of lactose from supersaturated solution. Food Bioprod. Process. 109:86-97. https: //doi.org/10.1016/j.fbp.2018.03.003.

Barbosa-Cánovas, G. V., F. Harte, and H. H. Yan. 2012. Particle size distribution in food powders. Food Eng. 1:303-328.
Berkovitch-Yellin, Z., J. Van Mil, L. Addadi, M. Idelson, M. Lahav, and L. Leiserowitz. 1985. Crystal morphology engineering by" tailor-made" inhibitors; a new probe to fine intermolecular interactions. J. Am. Chem. Soc. 107:3111-3122. https://doi.org/10.1021/ ja00297a017.

Belitz, H. D., W. Grosch, and P. Schieberle. 2009. Food Chemistry. 4th ed. Springer-Verlag, Heidelberg, Germany.

Berlin, E., P. Kliman, B. A. Anderson, and M. Pallansch. 1971. Calorimetric measurement of the heat of desorption of water vapor from amorphous and crystalline lactose. Thermochim. Acta 2:143-152. https://doi.org/10.1016/0040-6031(71)85043-8.

Bhargava, A., and P. Jelen. 1996. Lactose solubility and crystal growth as affected by mineral impurities. J. Food Sci. 61:180-184. https:/ /doi.org/10.1111/j.1365-2621.1996.tb14754.x.

Bogahawaththa, D., J. Chandrapala, and T. Vasiljevic. 2019. Thermal denaturation of bovine $\beta$-lactoglobulin in different protein mixtures in relation to antigenicity. Int. Dairy J. 91:89-97. https://doi .org/10.1016/j.idairyj.2018.10.004.

Botsaris, G. 1982. Effects of impurities in crystallization processes. Industrial Crystallization 81:123-135.

Butler, B. 1998. Modeling industrial lactose crystallisation. PhD thesis. University of Queensland, Brisbane, Australia.

Chandrapala, J., R. Wijayasinghe, and T. Vasiljevic. 2016. Lactose crystallization as affected by presence of lactic acid and calcium in model lactose systems. J. Food Eng. 178:181-189. https://doi.org/ 10.1016/j.jfoodeng.2016.01.019.

Dincer, T., M. Ogden, and G. Parkinson. 2009. Crystal growth mechanisms of the $\left(\begin{array}{lll}0 & 1 & 0\end{array}\right)$ face of $\alpha$-lactose monohydrate crystals. J. Cryst. Growth 311:2427-2432. https://doi.org/10.1016/j.jcrysgro .2009.02.030.

Drapier-Beche, N., J. Fanni, and M. Parmentier. 1998. Kinetics of the synthesis of lactose molecular compounds. J. Dairy Sci. 81:28262832. https://doi.org/10.3168/jds.S0022-0302(98)75841-2.

Gänzle, M. G., G. Haase, and P. Jelen. 2008. Lactose: Crystallization, hydrolysis and value-added derivatives. Int. Dairy J. 18:685-694 https://doi.org/10.1016/j.idairyj.2008.03.003.

Gombás, Á., P. Szabó-Révész, M. Kata, G. Regdon Jr., and I. Erős. 2002. Quantitative determination of crystallinity of $\alpha$-lactose monohydrate by DSC. J. Therm. Anal. Calorim. 68:503-510. https://doi.org/10.1023/A:1016039819247.

Haque, M. K., and Y. H. Roos. 2005. Crystallization and X-ray diffraction of spray-dried and freeze-dried amorphous lactose. Carbohydr. Res. 340:293-301. https://doi.org/10.1016/j.carres.2004 .11 .026 .

Hartel, R. 2019. Crystallization in foods. Pages 460-478 in Handbook of Industrial Crystallization. A. Myerson, D. Erdemir, and A. Lee, ed. Cambridge University Press, Cambridge, UK.

Herrington, B. 1934. Some physico-chemical properties of lactose: VI. The solubility of lactose in salt solutions; the isolation of a com- 
pound of lactose and calcium chloride. J. Dairy Sci. 17:805-814. https://doi.org/10.3168/jds.S0022-0302(34)93306-3.

Holsinger, V. H. 1988. Lactose. Pages 279-342 in Fundamentals of Dairy Chemistry. N. P. Wong, R. Jenness, M. Keeney, and E. H. Marth, ed. Springer, New York, NY.

Huppertz, T., and I. Gazi. 2016. Lactose in dairy ingredients: Effect on processing and storage stability1. J. Dairy Sci. 99:6842-6851. https://doi.org/10.3168/jds.2015-10033.

Islam, M. I. U., and T. A. G. Langrish. 2010. An investigation into lactose crystallization under high temperature conditions during spray drying. Food Res. Int. 43:46-56. https://doi.org/10.1016/j .foodres.2009.08.010.

Jelen, P., and S. T. Coulter. 1973. Effects of certain salts and other whey substances on the growth of lactose crystals. J. Food Sci. 38:1186-1189. https://doi.org/10.1111/j.1365-2621.1973.tb07234 .x.

Kaialy, W., M. D. Ticehurst, J. Murphy, and A. Nokhodchi. 2011. Improved aerosolization performance of salbutamol sulfate formulated with lactose crystallized from binary mixtures of ethanolacetone. J. Pharm. Sci. 100:2665-2684. https://doi.org/10.1002/ jps. 22483.

Kirk, J. H., S. E. Dann, and C. Blatchford. 2007. Lactose: A definitive guide to polymorph determination. Int. J. Pharm. 334:103-114. https://doi.org/10.1016/j.ijpharm.2006.10.026.

Lai, H. M., and S. J. Schmidt. 1990. Lactose crystallization in skim milk powder observed by hydrodynamic equilibria, scanning electron microscopy and $2 \mathrm{H}$ nuclear magnetic resonance. J. Food Sci. 55:994-999. https://doi.org/10.1111/j.1365-2621.1990.tb01582.x.

Laos, A. K., B. E. Kirs, C. A. Kikkas, and D. T. Paalme. 2007. Crystallization of the supersaturated sucrose solutions in the presence of fructose, glucose and corn syrup. Pages 16-20 in Proc. European Congress of Chemical Engineering (ECCE-6). Copenhagen, Denmark.

Listiohadi, Y., J. A. Hourigan, R. W. Sleigh, and R. J. Steele. 2009. Thermal analysis of amorphous lactose and alpha lactose monohydrate. Dairy Sci. Technol. 89:43-67. https://doi.org/10.1051/dst: 2008027.

Mandare, P. N., and V. G. Pangarkar. 2003. Semi-batch reactive crystallization of sodium perborate tetrahydrate: Effect of mixing parameters on crystal size. Chem. Eng. Sci. 58:1125-1133. https:// doi.org/10.1016/S0009-2509(02)00574-2.

Martinez, E., G. Hough, and A. Contarini. 1990. Sandiness prevention in dulce de leche by seeding with lactose microcrystals. J. Dairy Sci. 73:612-616. https://doi.org/10.3168/jds.S0022-0302(90)78710 -3 .

Mimouni, A., P. Schuck, and S. Bouhallab. 2005. Kinetics of lactose crystallization and crystal size as monitored by refractometry and laser light scattering: Effect of proteins. Lait 85:253-260. https:// doi.org/10.1051/lait:2005015.

Monshi, A., M. R. Foroughi, and M. R. Monshi. 2012. Modified Scherrer equation to estimate more accurately nano-crystallite size using XRD. World J. Nano Sci. Eng. 2:154-160.

Mullin, J. 1979. Crystal-growth in pure and impure systems. Przem. Chem. 58:180-184.

Nickerson, T. 1954. Lactose crystallization in ice cream. I. Control of crystal size by seeding. J. Dairy Sci. 37:1099-1105. https://doi .org/10.3168/jds.S0022-0302(54)91373-9.

Nickerson, T., and E. Moore. 1974. Alpha lactose and crystallization rate. J. Dairy Sci. 57:160-164. https://doi.org/10.3168/jds.S0022 $-0302(74) 84854-\mathrm{X}$

Nijdam, J., A. Ibach, K. Eichhorn, and M. Kind. 2007. An X-ray diffraction analysis of crystallised whey and whey-permeate powders. Carbohydr. Res. 342:2354-2364. https://doi.org/10.1016/j.carres 2007.08.001.

Parimaladevi, P., and K. Srinivasan. 2014. Influence of supersaturation level on the morphology of $\alpha$-lactose monohydrate crystals. Int. Dairy J. 39:301-311. https://doi.org/10.1016/j.idairyj.2014.08 .007 .

Pisponen, A., S. Pajumägi, H. Mootse, A. Sats, V. Poikalainen, and A. Karus. 2014. Effect of cooling rates and low crystallization tem- peratures on morphology of lactose crystals obtained from Ricotta cheese whey. Agron. Res. (Tartu) 12:787-792.

Raghavan, S., R. Ristic, D. Sheen, J. Sherwood, L. Trowbridge, and P. York. 2000. Morphology of crystals of $\alpha$-lactose hydrate grown from aqueous solution. J. Phys. Chem. B 104:12256-12262. https: //doi.org/10.1021/jp002051o.

Raghavan, S. L., R. I. Ristic, D. B. Sheen, and J. N. Sherwood. 2001. The bulk crystallization of $\alpha$-lactose monohydrate from aqueous solution. J. Pharm. Sci. 90:823-832. https://doi.org/10.1002/jps .1036.

Raut, D. M., A. Ravikiran, G. Deshpande, D. Patil, A. Patil, A. Deshmukh, D. M. Sakharkar, P. S. Bodke, and D. T. Mahajan. 2001. Dehydration of lactose monohydrate: Analytical and physical characterization. Pharm. Lett. 3:202-212.

Reid, S. D., and R. O. Fennema. 2008. Water and ice. Pages 17-83 in Fennema's Food Chemistry. 4th ed. S. Damodaran, L. K. Parkin, and R. O. Fennema, ed. Taylor \& Francis Group LLC, Boca Raton, FL.

Rjabova, A., V. Kirsanov, M. Strizhko, A. Bredikhin, V. Semipyatnyi, V. Chervetsov, and A. Galstyan. 2013. Lactose crystallization: Current issues and promising engineering solutions. Foods and Raw Materials 1(1). 10.12737/1559.

Roos, Y. 2009. Solid and liquid states of lactose. Pages 17-33 in Advanced Dairy Chemistry. 3rd ed. P. L. H. McSweeney and P. F Fox, ed. Springer Science+Business Media, LLC, New York, NY.

Roos, Y. H. 2002. Importance of glass transition and water activity to spray drying and stability of dairy powders. Lait $82: 475-484$. https://doi.org/10.1051/lait:2002025.

Sánchez-García, Y. I., S. K. Bhangu, M. Ashokkumar, and N. Gutiérrez-Méndez. 2018. Sonocrystallization of lactose from whey. Technological Approaches for Novel Applications in Dairy Processing: 51. 10.5772/intechopen.74759.

Sánchez-García, Y. I., N. Gutiérrez-Méndez, R. E. Orozco-Mena, V. H. Ramos-Sánchez, and M. Y. Leal-Ramos. 2019. Individual and combined effect of $\mathrm{pH}$ and whey proteins on lactose crystallization. Food Res. Int. 116:455-461. https://doi.org/10.1016/j.foodres .2018.08.061.

Scherrer, P. 1918. Nachrichten von der Koniglichen Gesellschaft der Wissenschaft zu, Gottingen, Bestimmung der Große und der inneren Struktur vonKolloidteilchen mittels Rontgenstrahlen. Mathematisch-physikalische Klasse 1:98.

van Kreveld, A., and A. S. Michaels. 1965. Measurement of crystal growth of $\alpha$-lactose. J. Dairy Sci. 48:259-265. https://doi.org/10 .3168/jds.S0022-0302(65)88213-3.

Visser, R. A. 1980. A natural crystal growth retarder in lactose. Neth. Milk Dairy J. 34:255-275.

Walstra, P. 2003. Crystallization. Pages 601-667 in Physical Chemistry of Foods. CRC Press, Boca Raton, FL.

Wijayasinghe, R., D. Bogahawaththa, T. Huppertz, J. Chandrapala, and T. Vasiljevic. 2019. Influence of lactic, citric and phosphoric acids on the properties of concentrated lactose solutions. Food Chem. 293:247-253. https://doi.org/10.1016/j.foodchem.2019.04 .065 .

Wijayasinghe, R., T. Vasiljevic, and J. Chandrapala. 2015. Waterlactose behavior as a function of concentration and presence of lactic acid in lactose model systems. J. Dairy Sci. 98:8505-8514. https://doi.org/10.3168/jds.2015-9959.

Wijayasinghe, R., T. Vasiljevic, and J. Chandrapala. 2016. Lactose behaviour in the presence of lactic acid and calcium. J. Dairy Res. 83:395-401. https://doi.org/10.1017/S0022029916000315.

Wolkers, W. F., H. Oldenhof, M. Alberda, and F. A. Hoekstra. 1998. A Fourier transform infrared microspectroscopy study of sugar glasses: Application to anhydrobiotic higher plant cells. Biochim. Biophys. Acta 1379:83-96. https://doi.org/10.1016/S0304 -4165(97)00085-8.

Wong, S. Y., and R. W. Hartel. 2014. Crystallization in lactose refining-A review. J. Food Sci. 79:R257-R272. https://doi.org/10 $.1111 / 1750-3841.12349$. 